\title{
HYDROCARBON PHOTOCHEMISTRY AND LYMAN ALPHA ALBEDO OF JUPITER ${ }^{1}$
}

\author{
YuK L. YunG \\ California Institute of Technology, Pasadena, California \\ AND \\ Darrell F. Strobel \\ Naval Research Laboratory, Washington, DC \\ Received 1979 December 6; accepted 1980 January 8
}

\begin{abstract}
A combined study of hydrocarbon and atomic hydrogen photochemistry is made to calculate self-consistently the $\mathrm{L} \alpha$ albedo of Jupiter. It is shown that the $\mathrm{L} \alpha$ emissions observed by Voyagers I and $I I$ can be explained by resonance scattering of sunlight. Precipitation of energetic particles from the magnetosphere can provide the large required source of atomic hydrogen, although the contribution of direct particle excitation to the disk-averaged brightness is insignificant. The variability of the $L \alpha$ brightness inferred from many observations in recent years is examined. The large difference in the brightness of the He $584 \AA$ resonance line observed by Pioneer and Voyager is briefly discussed. Driving the photochemistry by solar ultraviolet radiation alone yields a maximum mixing ratio of $\mathrm{C}_{2} \mathrm{H}_{6}+\mathrm{C}_{2} \mathrm{H}_{2}$ at $10^{-2}$ atm of about $4 \times 10^{-6}$. The possibility of additional $\mathrm{CH}_{4}$ dissociation from precipitation of magnetospheric particles is discussed. The photochemistry of $\mathrm{C}_{2} \mathrm{H}_{2}$ and $\mathrm{C}_{2} \mathrm{H}_{3}$ is sufficiently uncertain not to permit accurate calculations of their densities and the ratio $\mathrm{C}_{2} \mathrm{H}_{6} / \mathrm{C}_{2} \mathrm{H}_{2}$.
\end{abstract}

Subject headings: molecular processes - planets: abundances — planets: Jupiter

\section{INTRODUCTION}

The L $\alpha$ brightness of Jupiter has been measured by a number of workers (Moos and Fastie 1969; Rottman, Mount, and Freer 1973; Giles, Moos, and McKinney 1976; Carlson and Judge 1974; Bertaux et al. 1979; Broadfoot et al. 1979; Clarke et al. 1979; see Table 1). All observations previous to 1976 were summarized and discussed by Giles, Moos, and McKinney (1976). More recent observations were compared by Bertaux et al. (1979). The most interesting question is why the brightness is so variable. Analysis by Carlson and Judge (1971) and Wallace and Hunten (1973) have shown that the $\mathrm{L} \alpha$ brightness of Jupiter is primarily due to resonance scattering of incident sunlight by atomic hydrogen. The $\mathrm{L} \alpha$ albedo depends on at least the following: (a) production of $\mathrm{H}$ atoms from $\mathrm{H}_{2}$ and $\mathrm{CH}_{4}$ dissociation, (b) vertical eddy mixing in the atmosphere, $(c)$ photochemistry of the hydrocarbons, and $(d)$ thermal structure of the atmosphere. Each of the above factors has been considered in some approximate manner in the previous models, but never all at once on a self-consistent basis.

The photochemistry of hydrocarbons in the atmosphere of Jupiter has been studied by one of the authors (Strobel 1969, 1973, 1974) whose prediction of abundant $\mathrm{C}_{2} \mathrm{H}_{6}$ and $\mathrm{C}_{2} \mathrm{H}_{2}$ concentrations has been

\footnotetext{
${ }^{1}$ Contribution No. 3312 of the Division of Geological and Planetary Sciences, California Institute of Technology.
}

borne out by recent observations (Ridgway 1974; Combes et al. 1974; Tokunaga, Knacke, and Owen 1976; Orton and Aumann 1977; Hanel et al. 1979). A number of recent advances justify another examination of the hydrocarbon photochemistry in the Jovian atmosphere, in addition to the requirement of a self-consistent calculation of the $\mathrm{L} \alpha$ albedo. Calculations of the chemical composition of the deep atmosphere by Barshay and Lewis (1978) enable us now to select a more appropriate boundary condition for $\mathrm{C}_{2} \mathrm{H}_{6}$. There is strong evidence that the $\mathrm{C} / \mathrm{H}$ ratio for Jupiter must be significantly higher than the solar value, which was used in previous photochemical calculations (Wallace and Hunten 1978; Sato and Hansen 1979). In addition, there have been important revisions in $\mathrm{CH}_{4}$ and $\mathrm{C}_{2} \mathrm{H}_{6}$ photoabsorption cross sections (Mount, Warden, and Moos 1977; Mount and Moos 1978) and in the rate coefficients for threebody reactions $\mathrm{H}+\mathrm{CH}_{3}+\mathrm{M} \rightarrow \mathrm{CH}_{4}+\mathrm{M}$ and $\mathrm{CH}_{3}$ $+\mathrm{CH}_{3}+\mathrm{M} \rightarrow \mathrm{C}_{2} \mathrm{H}_{6}+\mathrm{M}$ at low pressure (Van den Bergh 1976; Troe 1977). The detection of extensive polar emissions by Broadfoot et al. (1979) suggests that a large flux of energetic particles precipitates into the upper atmosphere. This magnetospheric interaction can provide a large source of atomic hydrogen and possibly hydrocarbons. In this paper we assess the possible importance of this interaction on the $L \alpha$ albedo and hydrocarbon abundances observed by Voyager. 
TABLE 1

OBSERVATION OF L $\alpha$ BRIGHTNESS OF JUPITER ${ }^{a}$

\begin{tabular}{|c|c|c|c|c|}
\hline Date Observed & $\begin{array}{l}\text { L } \propto \text { Brightness } \\
\quad(4 \pi I[\mathrm{kR}])\end{array}$ & $\left(10^{11} \mathrm{~cm}^{-2} \mathrm{~s}^{-1} \AA^{-1}\right)$ & $\begin{array}{c}4 I / F_{J} \\
(\AA)\end{array}$ & References \\
\hline 1967 Dec. 5. & 4.0 & 3.2 & 0.34 & Moos and Fastie 1969 \\
\hline 1972 Jan. 25 . & 4.4 & 3.2 & 0.37 & Rottman et al. 1973 \\
\hline 1972 Sept. $1 \ldots \ldots \ldots \ldots \ldots \ldots$ & 2.2 & 3.0 & 0.20 & Giles et al. 1976 \\
\hline 1973 Dec. $1 \ldots \ldots \ldots \ldots \ldots \ldots$ & 0.4 & 2.4 & 0.045 & Carlson and Judge 1974 \\
\hline 1976 Jan. 5-Sept. 22 . . . . . . . . . & $2.8-5.3$ & 2.13 & $0.35-0.67$ & Bertaux et al. 1979 \\
\hline 1979 Jan. $31 \ldots \ldots \ldots \ldots \ldots \ldots$ & 14 & 5.1 & 0.74 & Broadfoot et al. 1979 \\
\hline 1978 Dec. $1 \ldots \ldots \ldots \ldots \ldots \ldots \ldots$. . . . . & 13 & 5.1 & 0.69 & Clarke et al. 1979 \\
\hline
\end{tabular}

${ }^{a}$ All brightness intensities refer to disk-averaged values in $\mathrm{kR}\left(10^{9}\right.$ photons $\left.\mathrm{cm}^{-2} \mathrm{~s}^{-1}\right)$. Respectively, $\pi F$ and $\pi F_{J}$ denote the solar L $\alpha$ fluxes at 1AU and 5.2AU. Bertaux et al. 1979 used simultaneous measurements of the $\mathrm{L} \alpha$ emission of the geocorona to derive the albedo of the planet. For the observations of Broadfoot et al. 1979 and Clarke et al. 1979 we used the solar flux measured by Rottman and Mount 1980 on 1979 June 5. All other values of the solar flux in the table are deduced on the basis of the Sun's $10.7 \mathrm{~cm}$ flux and Zurich sunspot number, and application of Vidal-Madjar's 1975 formula.

\section{PHOTOCHEMICAL MODEL}

The details of the photochemical model were presented in Tables 2-5 in Strobel (1973), whose notation we follow. The standard model atmosphere, model A, is shown in Figure 1. (We also consider a colder isothermal atmosphere, model B, with temperature equal to $150 \mathrm{~K}$, as described in Strobel 1973.) Altitude $0 \mathrm{~km}$ corresponds to a neutral number density of 1 $\times 10^{19} \mathrm{~cm}^{-3}$. The model assumes a bulk $\mathrm{He} / \mathrm{H}_{2}$ ratio equal to 0.11 by volume. We adopt a $\mathrm{CH}_{4} / \mathrm{H}_{2}$ mixing ratio of $1.7 \times 10^{-3}$, as required to interpret the visible and near-infrared $\mathrm{CH}_{4}$ bands of Jupiter (Sato and Hansen 1979). The temperature at $z=0 \mathrm{~km}$ is $110 \mathrm{~K}$ and varies linearly with $z$ to $385 \mathrm{~K}$ at $z=500 \mathrm{~km}$. This choice is consistent with the Voyager IR results in the 0-150 km region (Hanel et al. 1979). Above this height, the temperature rises to an asymptotic value of $1200 \mathrm{~K}$ at $\sim 1500 \mathrm{~km}$. The vertical structure of the upper atmosphere is described by the simple analytic representation of Bates and Patterson (1961). In a onedimensional photochemical model vertical transport for long-lived species is conveniently described by eddy

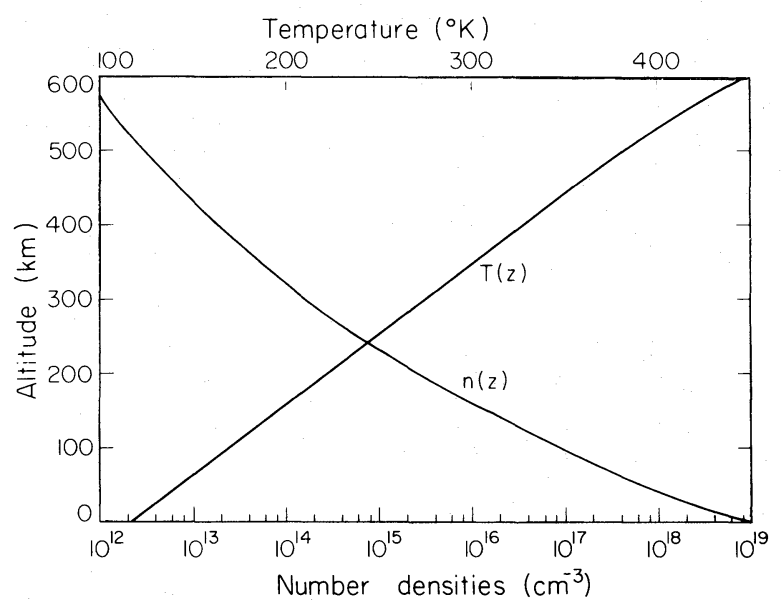

FIG. 1. - Number density and temperature profile for model A diffusion. The magnitude of the eddy diffusion coefficients $K(z)$ in the lower stratosphere is constrained by the requirement that it be compatible with the $\mathrm{NH}_{3}$ and $\mathrm{PH}_{3}$ photochemical destruction rate (Strobel 1977) and the CO abundance in the lower stratosphere (Strobel and Yung 1979). In the upper stratosphere, estimates of mixing rates can be derived from the $\mathrm{L} \alpha$ albedo of the planet (Wallace and Hunten 1973; Carlson and Judge 1976), if solar radiation determines the production rate of $\mathrm{H}$. However, in view of the large variability of the observed $L \alpha$ brightness, other factors may contribute. Eddy mixing in the upper atmosphere is considered an adjustable parameter in this work. The eddy diffusivity profile is expressed as

where

$$
K(z)=\frac{K_{1}(z) K_{2}}{K_{1}(z)+K_{2}}
$$

$$
K_{1}(z)=K_{0}\left(\frac{n(0)}{n(z)}\right)^{\gamma},
$$

$n(z)$ is the number density of the atmosphere at $z$, and $\gamma$ is a dimensionless number of order unity which measures the rate of increase of $K_{1}(z)$ with altitude. Realistic choices of the constants $K_{0}$ and $K_{2}$ for the Jovian atmosphere require $K_{2} \gg K_{0}$. Hence, in the lower atmosphere $K(z) \approx K_{1}(z)$. In the upper atmosphere $K_{1}(z) \gg K_{2}$, and in this limit $K(z) \approx K_{2}$. The functional form of $K(z)$ was chosen to ensure continuous derivatives everywhere and to limit $K(z)$ as $z$ $\rightarrow \infty$ to be much less than the molecular diffusion coefficients.

The major differences between the previous and the current models are summarized in Table 2 ; they represent the most important updates to the photochemical model since 1974. The adoption of the extremely slow reaction rate for $\mathrm{R} 10$ creates a problem as to the fate of $\mathrm{C}_{2} \mathrm{H}_{3}$ radicals in Jupiter's atmosphere. Since reaction R9 is much faster than R10 at all altitudes,

$$
\mathrm{C}_{2} \mathrm{H}_{3}+\mathrm{H} \rightarrow \mathrm{C}_{2} \mathrm{H}_{2}+\mathrm{H}_{2},
$$


TABLE 2

Major Differences in Photochemical Model between This Study and Strobel's Study ${ }^{a}$

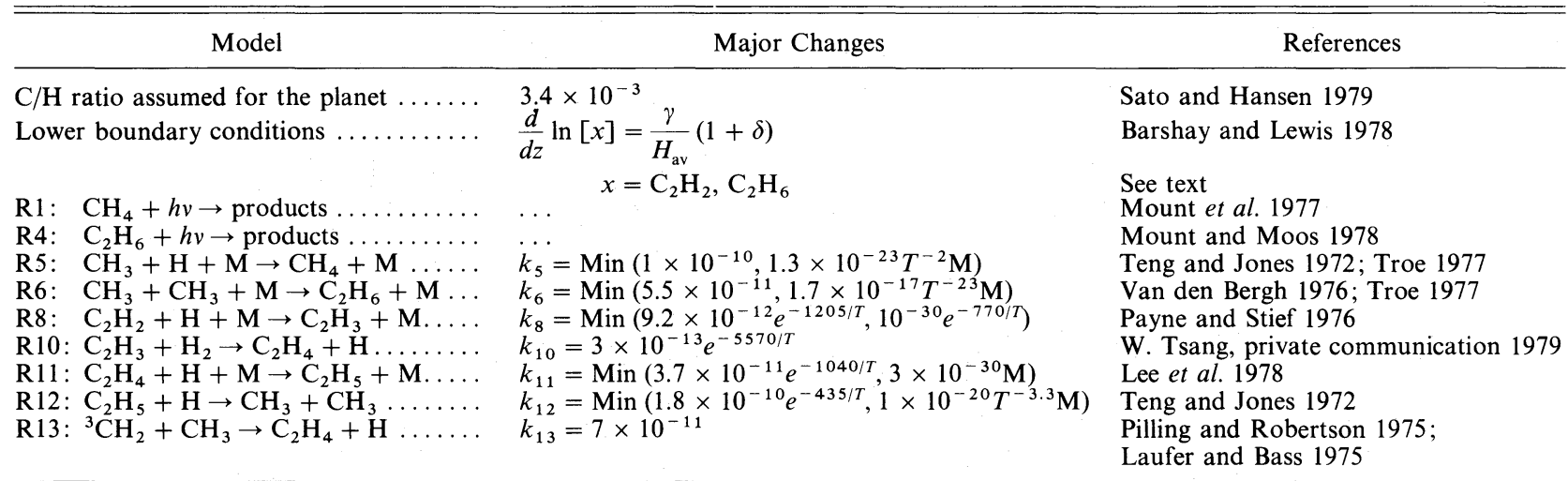

${ }^{\text {a }}$ The notation for reactions follows that in Tables 3 and 4 in Strobel 1973.

the catalytic cycle of $\mathrm{R} 8+\mathrm{R} 9$ is essentially unbroken and no significant conversion of $\mathrm{C}_{2} \mathrm{H}_{2}$ to $\mathrm{C}_{2} \mathrm{H}_{4}$ results (cf. Strobel 1973). We did not include a reaction suggested by Prasad, Capone, and Schneck (1975),

$$
\mathrm{C}_{2} \mathrm{H}_{3}+\mathrm{C}_{2} \mathrm{H}_{2} \rightarrow \mathrm{C}_{4} \mathrm{H}_{4}+\mathrm{H} \text {. }
$$

The heats of formation of $\mathrm{C}_{2} \mathrm{H}_{3}$ and $\mathrm{C}_{4} \mathrm{H}_{4}$ are not accurately enough known to determine whether this reaction is exothermic or endothermic. Even if this reaction were exothermic, it is estimated to be slow at Jovian temperatures, since its preexponential factor is $\sim 10^{-12} \mathrm{~cm}^{-3} \mathrm{~s}^{-1}$ with an activation energy of $\sim 2$ kcal mole ${ }^{-1}$ (Benson and Haugen 1967). We should also point out that Prasad, Capone, and Schneck (1975) did not treat the photochemistry of $\mathrm{C}_{4} \mathrm{H}_{4}$ produced in reaction (3) to determine whether it is recycled back to $\mathrm{C}_{2} \mathrm{H}_{2}$.

The photolysis of $\mathrm{C}_{2} \mathrm{H}_{2}$ is not completely understood, but Payne and Stief (1976) estimate that the quantum yield for $\mathrm{C}_{2} \mathrm{H}$ is $\sim 0.1$. The subsequent chemistry of $\mathrm{C}_{2} \mathrm{H}$ has recently been investigated by Laufer and Bass (1979). From their laboratory results, $\mathrm{C}_{2} \mathrm{H}$ should react preferentially with $\mathrm{H}_{2}$ in the stratosphere to form $\mathrm{C}_{2} \mathrm{H}_{2}$ and $\mathrm{H}$. The net result of $\mathrm{C}_{2} \mathrm{H}_{2}$ photolysis is thus destruction of $\mathrm{H}_{2}$. Our conclusion is that there is insufficient kinetic data available to adequately treat the chemistry of $\mathrm{C}_{2} \mathrm{H}_{2}$ and $\mathrm{C}_{2} \mathrm{H}_{3}$ in Jupiter's atmosphere. The absence of significant loss processes for $\mathrm{C}_{2} \mathrm{H}_{2}$ in our model leads to overestimates of its density when compared to observations. Rather than adopting a speculative loss process for the model, we chose to calculate the $\mathrm{C}_{2} \mathrm{H}_{2}$ density without any loss processes and caution the reader to interpret the resultant $\mathrm{C}_{2} \mathrm{H}_{2}$ densities as $\mathrm{C}_{2} \mathrm{H}_{2}$ plus other unknown species, e.g., $\mathrm{C}_{4} \mathrm{H}_{2}, \mathrm{C}_{4} \mathrm{H}_{4}$, additional $\mathrm{C}_{2} \mathrm{H}_{4}$, or even Danielson dust. ${ }^{2}$

${ }^{2}$ At the suggestion of D. M. Hunten at the 1979 DPS meeting in St. Louis, we shall use the term Danielson dust in the place of Axel dust (Axel 1972).
The $\mathrm{C}_{2} \mathrm{H}_{6}$ mixing ratio in the deep Jovian atmosphere is predicted by Barshay and Lewis (1978) to be less than $10^{-8}$. As a consequence, we anticipate a large flux of $\mathrm{C}_{2} \mathrm{H}_{6}$ from the stratosphere, where its mixing ratio could be as high as $10^{-5}$, to the deep atmosphere where it undergoes pyrolysis. The appropriate lower boundary condition in our model is (cf. Strobel 1975)

$$
\frac{d}{d z} \ln \left[\mathrm{C}_{2} \mathrm{H}_{6}\right]=\frac{\gamma}{H_{\mathrm{av}}}(1+\delta),
$$

where $H_{\mathrm{av}}$ is the scale height of the atmosphere, $\gamma$ is a dimensionless parameter defined by equation (2), and $\delta$ is a small correction factor proportional to the vertical gradient of temperature. The same boundary condition also applies to $\mathrm{C}_{2} \mathrm{H}_{2}$.

The primary sources of atomic hydrogen in the upper atmosphere are methane dissociation R1 and processes involving the EUV solar flux. The latter source has been estimated by Strobel (1973) to provide a mean flux of $\varphi_{0}=7 \times 10^{8}$ atoms cm $\mathrm{cm}^{-2} \mathrm{~s}^{-1}$ for solar activity consistent with Hinteregger's (1970) fluxes. There are additional sources of $\mathrm{H}$, through reactions associated with energetic electrons of magnetospheric origin, such as

$$
\begin{aligned}
& \mathrm{H}_{2}+e \rightarrow 2 \mathrm{H}+e, \\
& \mathrm{H}_{2}+e \rightarrow \mathrm{H}^{+}+\mathrm{H}+2 e, \\
& \mathrm{H}_{2}+e \rightarrow \mathrm{H}_{2}^{+}+2 e,
\end{aligned}
$$

followed by

$$
\begin{aligned}
\mathrm{H}^{+}+\mathrm{H}_{2}+\mathrm{H}_{2} & \rightarrow \mathrm{H}_{3}^{+}+\mathrm{H}_{2}, \\
\mathrm{H}_{2}^{+}+\mathrm{H}_{2} & \rightarrow \mathrm{H}_{3}^{+}+\mathrm{H}, \\
\mathrm{H}_{3}^{+}+e & \rightarrow \mathrm{H}_{2}+\mathrm{H} .
\end{aligned}
$$

Detailed modeling (Gladstone and Yung 1979) of the auroral observations by Broadfoot et al. (1979) suggests that the globally averaged flux of hydrogen atoms produced in the auroras could greatly exceed $\varphi_{0}$. 
Hydrogen atoms are destroyed mainly by

$$
\begin{gathered}
\mathrm{CH}_{3}+\mathrm{H}+\mathrm{M} \rightarrow \mathrm{CH}_{4}+\mathrm{M}, \\
\mathrm{H}+\mathrm{H}+\mathrm{M} \rightarrow \mathrm{H}_{2}+\mathrm{M},
\end{gathered}
$$

and the $\mathrm{C}_{2} \mathrm{H}_{2}$ catalytic cycle

$$
\begin{aligned}
\mathrm{C}_{2} \mathrm{H}_{2}+\mathrm{H}+\mathrm{M} \rightarrow \mathrm{C}_{2} \mathrm{H}_{3}+\mathrm{M}, \\
\mathrm{C}_{2} \mathrm{H}_{3}+\mathrm{H} \rightarrow \mathrm{C}_{2} \mathrm{H}_{2}+\mathrm{H}_{2}, \\
\hline \text { net } \quad \mathrm{H}+\mathrm{H} \rightarrow \mathrm{H}_{2} .
\end{aligned}
$$

$\mathrm{R} 5$ is the most important reaction for destruction of hydrogen. R8 and R9 become important below the $\tau(L \alpha)=1$ level for $\mathrm{CH}_{4}$. R7 limits the buildup of excessively large number densities of hydrogen.

The effect of energetic particles on the hydrocarbons is less clear. If the energy of the incident electrons exceeds $10^{5} \mathrm{eV}$, most of the particles are stopped below the homopause, where they can dissociate $\mathrm{CH}_{4}$. Direct reactions, such as

$$
\begin{aligned}
\mathrm{CH}_{4}+e & \rightarrow \mathrm{CH}_{3}+\mathrm{H}+e, \\
\mathrm{CH}_{4}+e & \rightarrow \mathrm{CH}_{4}^{+}+e, \\
\mathrm{CH}_{4}^{+}+e & \rightarrow \mathrm{CH}_{3}+\mathrm{H},
\end{aligned}
$$

are not important since $\mathrm{C} / \mathrm{H} \sim 10^{-3}$. Secondary processes via a $\mathrm{L} \alpha$ photon could become marginally important:

$$
\begin{aligned}
\mathrm{H}_{2}+e & \rightarrow \mathrm{H}^{*}+\mathrm{H}+e, \\
\mathrm{H}^{*} & \rightarrow \mathrm{H}+h v(\mathrm{~L} \alpha), \\
\mathrm{CH}_{4}+h v(\mathrm{~L} \alpha) & \rightarrow \mathrm{CH}_{2}+\mathrm{H}_{2} .
\end{aligned}
$$

Probably most important is the following sequence of reactions based on Munson and Field (1969) and Huntress (1977):

$$
\left.\begin{array}{rl}
\mathrm{H}_{2}+e & \rightarrow \mathrm{H}_{2}^{+}+2 e, \\
\mathrm{H}_{2}^{+}+\mathrm{H}_{2} & \rightarrow \mathrm{H}_{3}^{+}+\mathrm{H}, \\
\mathrm{H}_{3}^{+}+\mathrm{CH}_{4} & \rightarrow \mathrm{CH}_{5}^{+}+\mathrm{H}_{2}, \\
\mathrm{CH}_{5}{ }^{+}+\mathrm{C}_{2} \mathrm{H}_{2} & \rightarrow \mathrm{C}_{3} \mathrm{H}_{5}^{+}+\mathrm{H}_{2} \\
\mathrm{CH}_{5}{ }^{+}+\mathrm{C}_{2} \mathrm{H}_{4} & \rightarrow \mathrm{C}_{2} \mathrm{H}_{5}^{+}+\mathrm{CH}_{4} \\
\mathrm{C}_{2} \mathrm{H}_{5}{ }^{+}+\mathrm{C}_{2} \mathrm{H}_{2} & \rightarrow \mathrm{C}_{3} \mathrm{H}_{3}^{+}+\mathrm{CH}_{4} \\
& \rightarrow \mathrm{C}_{4} \mathrm{H}_{5}^{+}+\mathrm{H}_{2} \\
\mathrm{C}_{2} \mathrm{H}_{5}{ }^{+}+\mathrm{C}_{2} \mathrm{H}_{4} & \rightarrow \mathrm{C}_{3} \mathrm{H}_{5}^{+}+\mathrm{CH}_{4} \\
\mathrm{C}_{2} \mathrm{H}_{5}{ }^{+}+\mathrm{C}_{2} \mathrm{H}_{6} & \rightarrow \mathrm{C}_{4} \mathrm{H}_{9}^{+}+\mathrm{H}_{2}
\end{array}\right\} .
$$

Recombination of these complex hydrocarbon ions will lead to the formation of a variety of heavier hydrocarbons. Until further laboratory kinetics studies become available, we can only consider this scheme for additional destruction of $\mathrm{CH}_{4}$ and subsequent production of $\mathrm{C}_{2} \mathrm{H}_{6}$ and $\mathrm{C}_{2} \mathrm{H}_{2}$ in a qualitative manner:

$$
\mathrm{C}_{x} \mathrm{H}_{y}^{+}+e \rightarrow \mathrm{C}_{2} \mathrm{H}_{2}, \mathrm{C}_{2} \mathrm{H}_{4}, \mathrm{C}_{2} \mathrm{H}_{6} \text {, etc . }
$$

\section{RADIATIVE TRANSFER MODEL}

The basic atomic and molecular physics parameters that describe multiple scattering of the $L \alpha$ photons in the Jovian atmosphere are taken from Carlson and Judge (1971) and Wallace and Hunten (1973) and summarized in Table 4 . The cross section for resonance scattering of $L \alpha$ by atomic hydrogen in standard notation is

$$
\sigma\left(v-v_{0}\right)=\sigma_{0} \sqrt{ }(\pi) \Phi\left(\frac{v-v_{0}}{\Delta v_{\mathrm{D}}}\right),
$$

where

$$
\begin{aligned}
\Phi(x) & =\frac{\alpha}{\pi^{3 / 2}} \int_{-\infty}^{\infty} d u \frac{e^{-u^{2}}}{(x-u)^{2}+\alpha^{2}}, \\
\sigma_{0} & =\frac{\pi e^{2}}{m c} \frac{f}{\sqrt{ }(\pi) \Delta v_{\mathrm{D}}}, \\
\alpha & =\frac{\Delta v_{N}}{\Delta v_{\mathrm{D}}} .
\end{aligned}
$$

Note that

and

$$
\begin{aligned}
& \lim _{x \rightarrow 0} \Phi(x)=\frac{1}{\sqrt{ }(\pi)} e^{-x^{2}}, \\
& \lim _{x \rightarrow \infty} \Phi(x)=\frac{\alpha}{\pi} \frac{1}{1+x^{2}},
\end{aligned}
$$

$$
\int_{-\infty}^{\infty} d v \sigma\left(v-v_{0}\right)=\frac{\pi e^{2}}{m c} f .
$$

The most important absorber of a $L \alpha$ photon is methane, whose cross section is uniform over the width of the solar line.

With the prescribed thermal profile and calculated densities of $\mathrm{H}$ and $\mathrm{CH}_{4}$ from the photochemical model, we construct the scattering parameters, the optical depth $\tau$, and the single scattering albedo $\tilde{\omega}_{0}(\tau)$. The incident solar line is divided uniformly into 156 steps to achieve adequate resolution. The $\mathrm{L} \alpha$ albedo at each wavelength interval is calculated using a highly accurate (better than $10^{-3}$ ) invariant embedding algorithm for inhomogeneous atmospheres (Sato, Kawabata, and Hansen 1977). For nearly conservative cases we choose the lower boundary at optical depth $=100$, a choice that should simulate an infinite scattering atmosphere to better than $1 \%$, based on comparisons with results obtained using $\mathrm{H}$ functions. We assume that scattering of $L \alpha$ photons can be approximated by the Rayleigh phase function ${ }^{3}$ without complete frequency redistribution. The neglect of polarization and frequency redistribution should not introduce more than $10 \%$ total error (Hansen and Travis 1974; Wallace 1971).

\footnotetext{
${ }^{3}$ The phase function is nearly isotropic, but the difference between the Rayleigh and isotropic phase functions are small for albedo calculations.
} 
TABLE 3

Summary of Input Assumptions for Model Runs ${ }^{a}$

\begin{tabular}{|c|c|c|c|c|c|}
\hline Model & $\begin{array}{c}\text { Model } \\
\text { Atmosphere }\end{array}$ & $K_{0}$ & $K_{2}$ & $\varphi_{\mathrm{H}}$ & $\begin{array}{c}\text { Solar } \\
\text { L } \propto \text { Flux }\end{array}$ \\
\hline A11 & A & $1(3)$ & $1(5)$ & 1 & 1 \\
\hline A 12 & A & $1(3)$ & $1(6)$ & 1 & 1 \\
\hline $\mathrm{A} 13$ & A & 1 (3) & $1(7)$ & 1 & 1 \\
\hline A14 & A & 1 (3) & $1(8)$ & 1 & 1 \\
\hline A15 & A & $1(3)$ & $1(9)$ & 1 & 1 \\
\hline A21 & A & $3(2)$ & $1(5)$ & 1 & 1 \\
\hline A22 & A & $3(2)$ & $1(7)$ & 1 & 1 \\
\hline A23 & A & $3(2)$ & 1 (9) & 1 & 1 \\
\hline B11.. & B & $1(3)$ & $1(5)$ & 1 & 1 \\
\hline B12. . & B & $1(3)$ & $1(6)$ & 1 & 1 \\
\hline B13. & B & 1 (3) & $1(7)$ & 1 & 1 \\
\hline B14. . & B & 1 (3) & $1(8)$ & 1 & 1 \\
\hline B15. . & B & 1 (3) & $1(9)$ & 1 & 1 \\
\hline $\mathrm{C} 11$ & A & $1(3)$ & $1(5)$ & 10 & 1 \\
\hline $\mathrm{C} 12$ & A & $1(3)$ & $1(6)$ & 10 & 1 \\
\hline C13. & A & 1 (3) & $1(7)$ & 10 & 1 \\
\hline C14. & A & 1 (3) & $1(8)$ & 10 & 1 \\
\hline$\ldots \ldots$ & A & $1(9)$ & $1(9)$ & 10 & 1 \\
\hline $\mathrm{C} 21$. & A & $1(6)$ & $1(6)$ & 30 & 1 \\
\hline $\mathrm{C} 22$ & A & $1(7)$ & $1(7)$ & 30 & 1 \\
\hline$\ldots \ldots$ & A & $1(3)$ & $1(5)$ & 1 & 3 \\
\hline D12 & A & $1(3)$ & $1(6)$ & 1 & 3 \\
\hline D13 & A & 1 (3) & $1(7)$ & 1 & 3 \\
\hline D14 & A & $1(3)$ & $1(8)$ & 1 & 3 \\
\hline D15. & A & $1(3)$ & $1(9)$ & 1 & 3 \\
\hline
\end{tabular}

${ }^{a} K_{0}$ and $K_{2}$ are as defined by equations (1) and (2) in units of $\mathrm{cm}^{2} \mathrm{~s}^{-1}$. The parameter $\gamma=1 . \varphi_{\mathrm{H}}$ is the total column production of hydrogen atoms in the units $7 \times 10^{8}$ atoms $\mathrm{cm}^{-2} \mathrm{~s}^{-1}$. The solar $\mathrm{L} \alpha$ flux refers to the integrated flux of photons at $1 \mathrm{AU}$ in units 3.5 $\times 10^{11}$ photons $\mathrm{cm}^{-2} \mathrm{~s}^{-1}$. Model $\mathrm{A}$ is a warm atmosphere as described in Figure 1. Model B is an isothermal atmosphere at $150 \mathrm{~K}$ as described in Strobel 1973. The numbers $a(b)$ read as $a \times 10^{b}$.

\section{DISCUSSION OF RESULTS}

A fairly comprehensive set of models has been generated to understand the sensitivity of the major observable constituents, $\mathrm{C}_{2} \mathrm{H}_{6}, \mathrm{C}_{2} \mathrm{H}_{2}$, and $\mathrm{H}$ to the input parameters. The essential features of the models are summarized in Table 3 . The A and B series are designed to explore the dependence on eddy diffusion coefficient and temperature when the production of $\mathrm{H}$

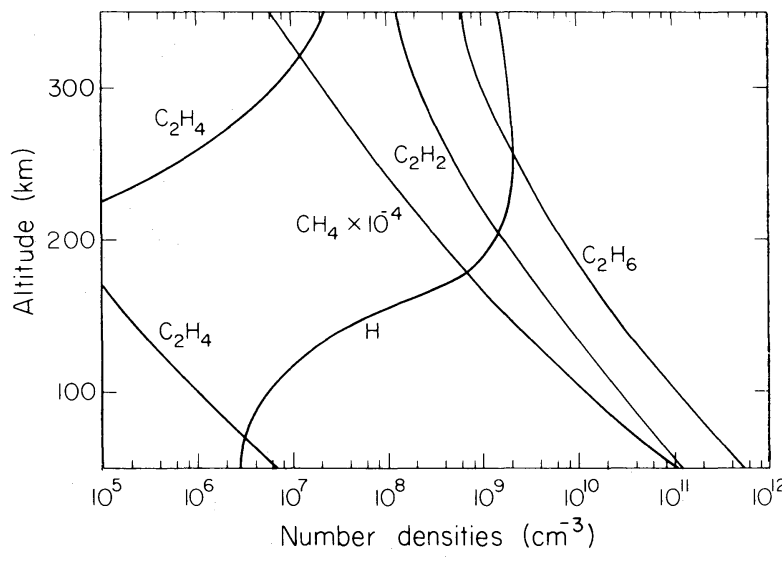

FIG. 2.-Number densities of major species computed with model A13. See Table 3 for input parameters used in model calculations for this and all subsequent figures.

is due solely to solar EUV radiation, estimated by Strobel (1973) to be $7 \times 10^{8}$ atoms $\mathrm{cm}^{-2} \mathrm{~s}^{-1}$. The C series explores the consequence of atomic hydrogen production associated with energetic particle precipitation observed by Broadfoot et al. (1979). The possible impact of reactions $(17 \mathrm{c})$ on the abundances of $\mathrm{C}_{2} \mathrm{H}_{6}$ and $\mathrm{C}_{2} \mathrm{H}_{2}$ is investigated in the $\mathrm{D}$ runs. The net result is enhanced dissociation of $\mathrm{CH}_{4}$, which is equivalent to an increased incident solar flux.

Our discussion of the numerical results will concentrate on observable constituents: $\mathrm{C}_{2} \mathrm{H}_{6}, \mathrm{C}_{2} \mathrm{H}_{2}$, and $\mathrm{H}$. Figure 2 illustrates altitude profiles for the major hydrocarbon species computed in model A13 with solar UV radiation as the only source and an "average" $L \alpha$ reflectivity (cf. Fig. 5). The results would have been a plausible prediction for the Voyager encounter. The eddy diffusion coefficients were $K_{0}$ $=10^{3}$ and $K_{2}=10^{7} \mathrm{~cm}^{2} \mathrm{~s}^{-1}$. Figure 3 shows the dependence of $\mathrm{C}_{2} \mathrm{H}_{6}$ on the choice of various input parameters. The $\mathrm{C}_{2} \mathrm{H}_{6}$ concentration increases with higher $K$ in the upper atmosphere and lower $K$ at the lower boundary, with lower temperatures in the inversion region, and enhanced production by particle precipitation. The $\mathrm{C}_{2} \mathrm{H}_{6}$ dissociation rate is not neglig-

TABLE 4

Values of Important Parameters in L $\alpha$ Brightness Calculations ${ }^{a}$

\begin{tabular}{|c|c|}
\hline Parameter & Value \\
\hline $\begin{array}{l}\text { Natural line width } \Delta v_{N} \ldots \ldots \ldots \ldots \ldots \ldots \ldots \\
\text { Doppler line width } \Delta v_{\mathrm{D}} \ldots \ldots \ldots \ldots \ldots \ldots\end{array}$ & $\begin{array}{l}4.986 \times 10^{7} \mathrm{~s}^{-1} \\
1.061 \times 10^{9} \sqrt{ }(T) \mathrm{s}^{-1}\end{array}$ \\
\hline Cross section at line center $\sigma_{0}=\frac{\pi e^{2}}{m c} \frac{f}{\pi \Delta v_{\mathrm{D}}} \ldots \ldots \ldots \ldots \ldots \ldots \ldots \ldots \ldots$ & $5.876 \times 10^{-12} \frac{1}{\sqrt{ }(T)} \mathrm{cm}^{2}$ \\
\hline 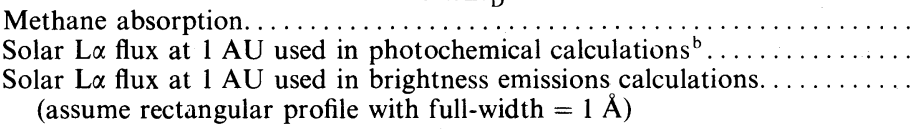 & $\begin{array}{l}1.9 \times 10^{-17} \mathrm{~cm}^{2} \\
3.5 \times 10^{11} \text { photons cm-2 } \mathrm{s}^{-1} \\
5.1 \times 10^{11} \text { photons } \mathrm{cm}^{-2} \mathrm{~s}^{-1} \AA^{-1}\end{array}$ \\
\hline
\end{tabular}

a $T$ is temperature in kelvins. The numerical values are from Carlson and Judge 1971. The solar L $\alpha$ flux is from Rottman and Mount 1980.

${ }^{b}$ This assumes about $70 \%$ of the incident solar $\mathrm{L} \alpha$ is absorbed by $\mathrm{CH}_{4}$. The remaining $30 \%$ is reflected. 


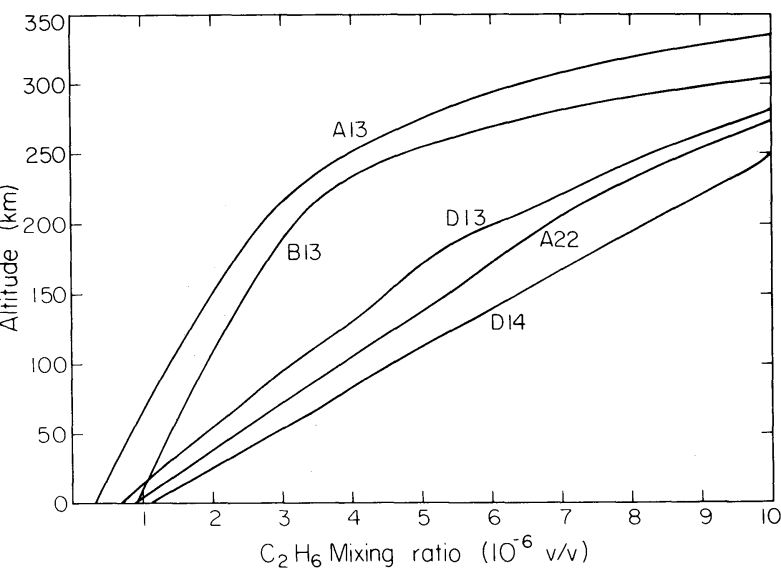

Fig. 3. $-\mathrm{C}_{2} \mathrm{H}_{6}$ mixing ratio by volume computed with models A13, A22, B13, D13, and D14.

ible in comparison to the mixing rate for small $K$. With the $\mathrm{CH}_{4}$ absorption cross sections based on Mount, Warden, and Moos (1977), we find that $\mathrm{CH}_{4}$ does not effectively shield $\mathrm{C}_{2} \mathrm{H}_{6}$ from dissociation as in previous calculations (Strobel 1973, 1974). Consequently the $\mathrm{C}_{2} \mathrm{H}_{6}$ density is sensitive to $K(z)$ in the lower stratosphere. Also, at the lower boundary, downward mixing of $\mathrm{C}_{2} \mathrm{H}_{6}$ from its source region is a major sink. Our calculations suggest an upper limit on the $\mathrm{C}_{2} \mathrm{H}_{6}$ mixing ratio of $3 \times 10^{-6}$ at the $p=10^{-2}$ atm level. We emphasize that our lower mixing ratio (compared to the large mixing ratio of Strobel 1974 with $\varphi=0$ lower boundary condition) results from the boundary condition (5) and the larger $\mathrm{C}_{2} \mathrm{H}_{6}$ dissociation rate. According to Tokunaga, Knacke, and Owen (1976) their observations would require an inversion layer at $190 \mathrm{~K}$ if the $\mathrm{C}_{2} \mathrm{H}_{6}$ mixing ratio were only $\sim 5 \times 10^{-7}$. However, an inversion layer at $150 \mathrm{~K}$ requires a mixing ratio of $10^{-5}$ to be in accord with their observations. Indeed, Orton and Aumann (1977) prefer a warm inversion layer with $T>155 \mathrm{~K}$ and increasing with height to $\sim 200 \mathrm{~K}$ at $p=10^{-4} \mathrm{~atm}$. The results of Figure 3 in conjunction with mixing ratios of $\mathrm{C}_{2} \mathrm{H}_{6}$ inferred from Voyager IR data may indicate sources of $\mathrm{C}_{2} \mathrm{H}_{6}$ and $\mathrm{C}_{2} \mathrm{H}_{2}$ in addition to solar UV dissociation (Hanel 1979). It is important to recognize the time constants for various processes in the upper atmosphere. The lifetime associated with the column integrated hydrocarbon abundance $\left(\mathrm{C}_{2} \mathrm{H}_{6}+\mathrm{C}_{2} \mathrm{H}_{2}\right)$ exceeds $100 \mathrm{yr}$ and thus should not vary significantly in response to changes in auroral activity and the column integrated atomic hydrogen abundance. The lifetime associated with the column integrated atomic hydrogen abundance is of order 100 days. Steady state calculations of $\mathrm{C}_{2} \mathrm{H}_{6}$ and $\mathrm{C}_{2} \mathrm{H}_{2}$ densities in the lower stratosphere for Voyager conditions may be underestimates as a consequence of the large $\mathrm{H}$ atom concentration which suppresses recombination of $\mathrm{CH}_{3}$ radicals to $\mathrm{C}_{2} \mathrm{H}_{6}$.

Figure 4 shows the distribution of $\mathrm{H}$ in a number of models. The abundance of $\mathrm{H}$ above the methane

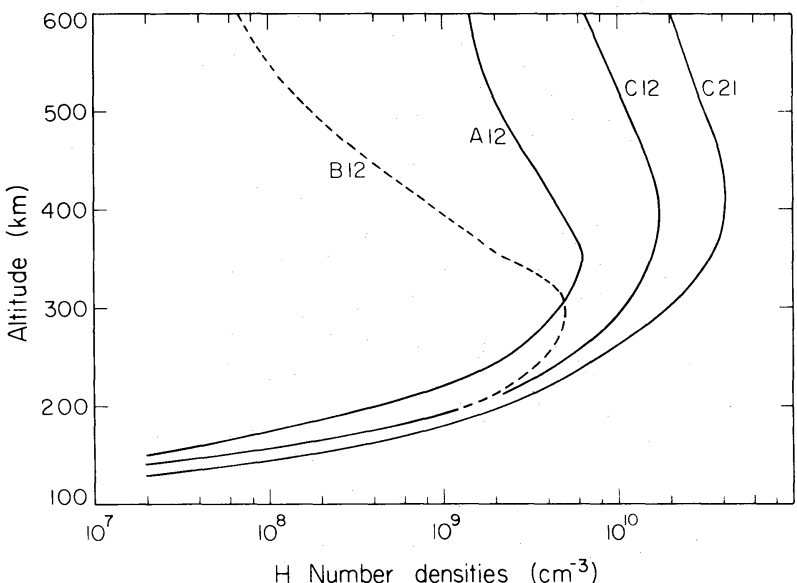

Fig. 4.-Atomic $\mathrm{H}$ number densities computed with models $\mathrm{A} 12, \mathrm{~B} 12, \mathrm{C} 12$, and $\mathrm{C} 21$.

absorption layer is a sensitive function of the eddy diffusion coefficient in the upper atmosphere $K_{2}$ and the flux of hydrogen atoms produced from particle precipitation. The reflectivity $4 I / F_{J}$, as defined by Wallace and Hunten (1973), is calculated for the various models and summarized in Figure 5. The curves $\mathrm{A}$ and $\mathrm{B}$ roughly reproduce the results previously obtained by Wallace and Hunten (1973), but

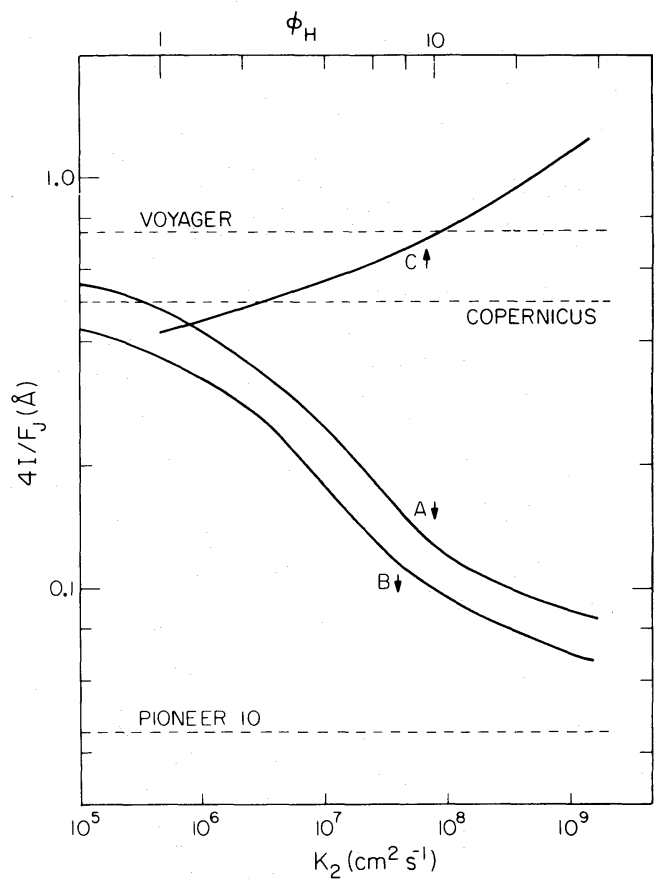

FIG. 5.-Disk-averaged reflectivity $4 I / F_{J}$ at $\mathrm{L} \alpha$ in $\AA$ units. The curves A and B were computed with models $A_{i j}$ and $B_{i j}$, respectively. The abscissa is the eddy diffusion coefficient in the upper atmosphere $K_{2}$. The curve C was computed using model atmosphere A with $K_{2}$ $=10^{6} \mathrm{~cm}^{2} \mathrm{~s}^{-1}$. The abscissa is the flux of hydrogen atoms at the upper boundary in units of $7 \times 10^{8}$ atoms cm-2 $\mathrm{s}^{-1}$. The dashed lines show the mean values of $4 I / F_{J}$ as measured by Pioneer 10 Copernicus, and Voyager (see Table 1). 
are consistently higher by $\sim 30 \%$. This may be partly due to the use of a Rayleigh phase function rather than an isotropic phase function for scattering of $L \alpha$ photons by $\mathrm{H}$ atoms. We conclude that the $\mathrm{L} \alpha$ albedo increases slightly with temperature, and the exceedingly high temperature $(\sim 1200 \mathrm{~K})$ in the thermosphere of model A has practically no effect. The reason is that most of the photons are scattered deep in the atmosphere from the Lorentz wings of the $\mathrm{L} \alpha$ line. The curve $C$ was computed to test the sensitivity of $4 I / F_{J}$ to $\varphi_{\mathrm{H}}$. In the standard model, we used model atmosphere $\mathrm{A}, K_{0}=10^{3}, K_{2}=10^{6} \mathrm{~cm}^{2} \mathrm{~s}^{-1}$ and $\varphi_{\mathrm{H}}=\varphi_{0}=7$ $\times 10^{8}$ atoms $\mathrm{cm}^{-2} \mathrm{~s}^{-1}$. The value of $\varphi_{\mathrm{H}}$ was then varied between $\varphi_{0}$ and $30 \varphi_{0}$.

Broadfoot et al. (1979) reported a disk-averaged L $\alpha$ brightness of $14 \mathrm{kR}$. Although no measurement of the solar $\mathrm{L} \alpha$ intensity was made during the Voyager encounter, a solar $\mathrm{L} \alpha$ flux of $3.75 \times 10^{11}$ photons $\mathrm{cm}^{-2} \mathrm{~s}^{-1} \AA^{-1}$ is estimated on the basis of the solar $10.4 \mathrm{~cm}$ flux (Vidal-Madjar 1975). A slightly higher flux of $5.1 \times 10^{11}$ photons $\mathrm{cm}^{-2} \mathrm{~s}^{-1} \AA^{-1}$ was measured by Rottman and Mount (1980) on 1979 June 5. Only a small fraction of the $14 \mathrm{kR}$ can be due to direct excitation by energetic particles. Our reasons are twofold. First, the night-side $\mathrm{L} \alpha$ intensity is less than $1 \mathrm{kR}$ (Sandel et al. 1979). Second, the center-to-limb variation of the observed $\mathrm{L} \alpha$ intensities is in good agreement with that predicted for resonance scattering, but not with that due to particle excitation as shown in Figure 6 (Canahan and Zipf 1977; Gladstone and Yung 1979). The center-to-limb variation of $\mathrm{L} \alpha$ intensities could offer additional confirmation of the scattering in the Lorentz wing. The dashed line in Figure 6 was computed by arbitrarily restricting the scattering to within 6 Doppler units from the core and is not in good agreement with observation. However, we need higher-quality data before we can settle this issue.

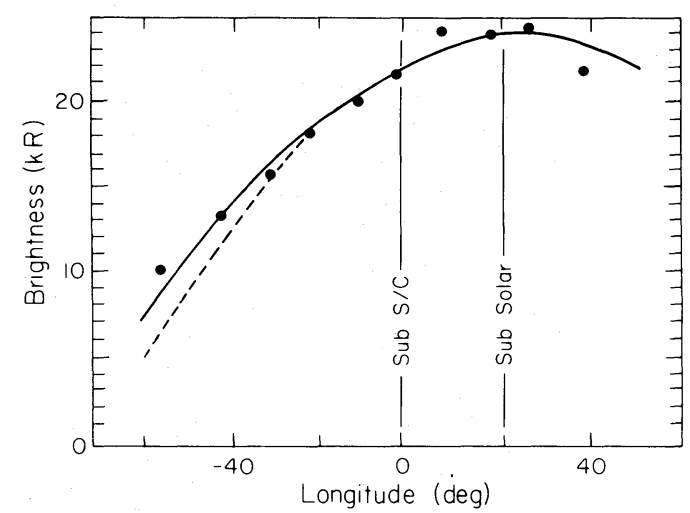

FIG. 6.-L $\alpha$ brightness as a function of longitude computed with model $\mathrm{C} 12$ for the same viewing geometry as described by Broadfoot et al. 1979. The intensity at $20^{\circ}$ has been normalized to $24 \mathrm{kR}$. The dashed line results from arbitrarily cutting off the emission line profile beyond about 6 Doppler units and renormalizing the intensity.
The observed variability of the $\mathrm{L} \alpha$ brightness (cf. Table 1 and Bertaux et al. 1979) suggests that the lifetime of atomic hydrogen in the Jovian thermosphere is less than a year. This implies an eddy diffusion coefficient at the homopause of more than $\sim 10^{6} \mathrm{~cm}^{2} \mathrm{~s}^{-1}$. From the results of Figure 5 we are forced to conclude that the Voyager $\mathrm{L} \alpha$ brightness requires energetic particle dissociation of $\mathrm{H}_{2}$ rather than a very low eddy diffusion coefficient. The principal problem in understanding the variability of Jupiter's upper atmosphere is the Pioneer $10 \mathrm{UV}$ photometer results (Carlson and Judge 1974). From Table 1 we note the reflectivity varies by a factor of 2 about a central value of $0.4 \AA$, with the exception of the Pioneer 10 results. From Figure 5 we infer that modest changes in $\mathrm{H}$ production, temperature, and eddy diffusion coefficient would easily explain this factor of 2 variability. However, the very large increase in $K_{2}$ and possibly temperature decrease required to understand Pioneer 10 UV results are puzzling. It should be noted that the Pioneer results are at least internally self-consistent. Assuming a $\mathrm{He} / \mathrm{H}_{2}$ ratio equal to 0.11 (Hanel et al. 1979), a very high eddy diffusion coefficient $\left(K_{2} \gtrsim 10^{8} \mathrm{~cm}^{2} \mathrm{~s}^{-1}\right)$ is required to account for the Pioneer observation of $5.2 \mathrm{R}$ emission in the shortwavelength channel. Broadfoot et al. (1979) reported an upper limit of $0.1 \mathrm{R}$ for the $584 \AA$ resonance emission of He. If confirmed, this would imply a much lower $K_{2} \approx 10^{5} \mathrm{~cm}^{2} \mathrm{~s}^{-1}$. It is conceivable that the atmosphere had undergone orders of magnitude of change in $K_{2}$ in the last few years. But until further evidence becomes available on the variability of the upper atmosphere, the Pioneer 10 results should be taken with reservation.

\section{CONCLUSIONS}

The high disk-averaged $L \alpha$ emission observed by Broadfoot et al. (1979) can be explained by resonance scattering of sunlight by hydrogen atoms. These observations require a larger source of $\mathrm{H}$ than solar EUV radiation. We suggest precipitation of magnetospheric particles to dissociate $\mathrm{H}_{2}$ and heat the upper atmosphere and estimate an average column production rate of at least $7 \times 10^{9}$ atoms $\mathrm{cm}^{-2} \mathrm{~s}^{-1}$, about 10 times more than solar EUV can produce. This is consistent with auroral emissions observed by Voyager. A low eddy diffusion coefficient alone cannot account for the observed $\mathrm{L} \alpha$ brightness; our calculations suggest $K_{2} \approx 10^{6}-10^{7} \mathrm{~cm}^{2} \mathrm{~s}^{-1}$. A value of $K_{2} \approx 10^{6}$ requires an $\mathrm{H}$ column production rate of 7 $\times 10^{9}$, whereas, $K_{2} \approx 10^{7}$ requires a production rate of $\sim 7 \times 10^{10}$ to obtain the Voyager observed albedo. For the average reflectivity, $4 I / F_{J} \approx 0.4 \AA$ in Table 1 , we infer $K_{2} \approx 10^{7} \mathrm{~cm}^{2} \mathrm{~s}^{-1}$ for solar production of $\mathrm{H}$ only.

To account for the inferred abundances of the hydrocarbons $\left(\mathrm{C}_{2} \mathrm{H}_{6}+\mathrm{C}_{2} \mathrm{H}_{2}\right)$ our updated model 
requires a low eddy coefficient at the tropopause $\left(10^{-1} \mathrm{~atm}\right) K_{0} \approx 10^{3} \mathrm{~cm}^{2} \mathrm{~s}^{-1}$ and a fairly high eddy coefficient at the homopause $K_{2} \approx 10^{7} \mathrm{~cm}^{2} \mathrm{~s}^{-1}$. Since -1 the lifetime for total (column integrated) $\mathrm{C}_{2}$ compounds in the stratosphere exceeds $100 \mathrm{yr}$, the values for $K_{0}$ and $K_{2}$ deduced from our calculations are an average over this period of time. This is consistent with average conditions inferred from $L \alpha$ albedo observations. We also suggest that magnetospheric particle precipitation may produce $\mathrm{CH}_{4}$ dissociation rates in excess of solar UV radiation during a certain portion of this period when solar activity is high.

We thank A. L. Broadfoot and his team for providing us with preliminary data, G. R. Gladstone, and $\mathrm{W}$. Huntress for helpful discussion. We thank the referee D. M. Hunten for improving our paper in many ways. This research was supported by NASA contract NSG-7376 to the California Institute of Technology under the Planetary Atmosphere Program.

\section{REFERENCES}

Axel, L. 1972, Ap. J., 173, 451.

Barshay, S. S., and Lewis, J. S. 1978, Icarus, 33, 593.

Bates, D. R., and Patterson, T. N. L. 1961, Planet. Space Sci, 5, 257.

Benson, S. W., and Haugen, G. R. 1967, J. Phys. Chem., 71, 4404.

Bertaux, J. L., Feston, M., Barker, E. S., and Jenkins, E. B. 1979, preprint.

Broadfoot, A. L., et al. 1979, Science, 204, 979.

Canahan, B. L., and Zipf, E. C. 1977, Phys. Rev. A, 16, 991.

Carlson, R. W., and Judge, D. L. 1971, Planet. Space Sci., 19, 327. -. 1974, J. Geophys. Res., 79, 3623.

- 1976, Jupiter, ed. T. Gehrels (Tucson: University of Arizona Press), pp. 418-40.

Clarke, J. T., Fastie, W. G., Feldman, P. D., Moss, H. W., Weaver, H. A., and Opal, C. B. $1979, E O S$, in press.

Combes, M., Encrenaz, Th., Vapillon, L., and Zeau, Y. 1974, Astr. Ap., 34, 33.

Giles, J. W., Moos, H. W., and McKinney, W. R. 1976, J. Geophys. Res., 81, 5797.

Gladstone, G. R., and Yung, Y. L. 1979, Bull. AAS, 11, 588.

Hanel, R. 1979, paper presented at the 1979 DPS meeting, in St. Louis.

Hanel, R., et al. 1979, Science, 204, 992.

Hansen, J. E., and Travis, L. D. 1974, Space Sci. Rev., 16, 527.

Hinteregger, H. E. 1970, Ann. Geophys., 26, 547.

Huntress, W. T., Jr. 1977, Ap. J. Suppl., 33, 495.

Laufer, A. H., and Bass, A. M. 1975, J. Phys. Chem., 79, 1635. 1979, J. Phys. Chem., 83, 310.

Lee, J. T., Michaels, J. V., Payne, W. A., and Stief, L. J. 1978, J. Chem. Phys., 68, 1817.

Moos, H. W., and Fastie, W. G. 1969, Ap. J., 155, 887.

Mount, G. H., and Moos, H. W. 1978, Ap. J., 224, 135

Mount, G. H., Warden, E. S., and Moos, H. W. 1977, Ap. J. (Letters), 214, L47.
Munson, M. S. B., and Field, F. H. 1969, J. Am. Chem. Soc., 91, 3413.

Orton, G. S., and Aumann, H. H. 1977, Icarus, 32, 431

Payne, W. A., and Stief, L. J. 1976, J. Chem. Phys., 64, 1150.

Pilling, M. J., and Robertson, J. A. 1975, Chem. Phys. Letters, 33, 336.

Prasad, S. S., Capone, L. A., and Schneck, L. J. 1975, Geophys. Res. Letters, 2, 161

Ridgway, S. T. 1974, Ap. J. (Letters), 187, L41.

Rottman, G. J., Moos, H. W., and Freer, C. S. 1973, Ap. J. (Letters), 184, L89.

Rottman, G. J., and Mount, G. H. 1980, to be published. Sandel, B. R., et al. 1979, Science, in press.

Sato, M., and Hansen, J. E. 1979, J. Atmos. Sci., 36, 1133.

Sato, M., Kawabata, K., and Hansen, J. E. 1977, Ap. J., 216, 947.

Strobel, D. F. 1969, J. Atmos. Sci., 26, 906.

1973, J. Atmos. Sci., 30, 489.

1974, Ap. J. (Letters), 192, L47-49.

1975, Rev. Geophys. Space Phys., 13, 372.

1977, Ap. J. (Letters), 214, L97-99.

Strobel, D. F., and Yung, Y. L. 1979, Icarus, 37, 256.

Teng, L., and Jones, W. E. 1972, J. Chem. Soc. Faraday Trans., I, 68, 1267.

Tokunaga, A., Knacke, R. F., and Owen, T. 1976, Ap. J., 209, 294.

Troe, J. 1977, J. Chem. Phys., 66, 4758.

Van den Bergh, H. E. 1976, Chem. Phys. Letters, 43, 201.

Vidal-Madjar, A. 1975, Solar Phys., 40, 69.

Wallace, L. 1971, Planet. Space Sci., 19, 377.

Wallace, L., and Hunten, D. M. 1973, Ap. J., 182, 1013.

- 1978, Rev. Geophys. Space Phys., 16, 289.

Yuk L. Yung: Department of Geological and Planetary Sciences, 170-25, California Institute of Technology, Pasadena, CA 91125

DARrell F. Strobel: Naval Research Laboratory, Washington, DC 20375 